\title{
Electrocardiographic and enzymatic correlations with outcome in neonates with hypoxic-ischemic encephalopathy
}

\author{
Jyoti Agrawal', Gauri S Shah'*, Prakash Poudel ${ }^{1}$, Nirmal Baral ${ }^{2}$, Ajay Agrawal ${ }^{3}$ and Om P Mishra ${ }^{4}$
}

\begin{abstract}
Background: Perinatal asphyxia leading to hypoxic-ischemic encephalopathy (HIE) is a common problem causing multi organ dysfunction including myocardial involvement which can affect the outcome.

Objective: To evaluate the myocardial dysfunction in neonates having HIE by electrocardiographic(ECG) and cardiac enzymes (CK Total, CK-MB and Troponin I) and find out the relationship with HIE and outcome.

Design/Methods: This was a hospital based prospective study. Sixty term neonates who had suffered perinatal asphyxia and developed HIE were enrolled. Myocardial involvement was assessed by clinical, ECG, and CK Total, CK-MB and Troponin I measurements.

Results: Of 60 cases, 13(21.7\%) were in mild, 27(45\%) in moderate and 20(33.3\%) belonged to severe,HIE. ECG was abnormal in 46 (76.7\%); of these 19 (41.3\%) had grade I, 13 (28.2\%) grades II and III each and 1 (2.1\%) with grade IV changes. Serum levels of CK Total, CK- MB and Troponin I were raised in 54 (90\%), 52 (86.6\%) and 48 (80\%) neonates, respectively. ECG changes and enzymatic levels showed increasing abnormalities with severity of HIE, and the differences among different grades were significant $(p=0.002,0.02,<0.001$ and 0.004 , respectively). Nineteen (32\%) cases died during hospital stay. The non- survivors had high proportion of abnormal ECG $(p=0.024)$, raised levels of CK-MB ( $p=0.018)$ and Troponin I $(p=0.008)$ in comparison to survivors.
\end{abstract}

Conclusions: Abnormal ECG and cardiac enzymes levels are found in HIE and can lead to poor outcome due to myocardial damage Early detection can help in better management and survival of these neonates.

Keywords: Perinatal asphyxia, HIE, Myocardial dysfunction

\section{Introduction}

Perinatal asphyxia is a common problem with the incidence varying from $0.5-2 \%$ of live births $[1,2]$. It accounts for 9.7/1000 live births and contributes for 30\% of neonatal mortality in Nepal [3]. It is an important cause of admission to neonatal intensive care units (NICU) with multi organ dysfunction [4]. When an asphyxic event occurs, it leads to a series of physiological mechanisms in order to preserve the function of vital organs (brain and heart), whereas other organs such as the kidneys, gastrointestinal tract, and skin are affected to a varying degree based on the duration of the episode

\footnotetext{
* Correspondence: gaurishankarshah@live.com

${ }^{1}$ Departments of Pediatrics and Adolescent Medicine, B.P. Koirala Institute of Health Sciences, Dharan, Nepal

Full list of author information is available at the end of the article
}

[5,6]. However, in spite of compensatory mechanisms, it may progress to hypoxic- ischemic encephalopathy (HIE) involving the brain and heart [7].

The incidence of cardiac dysfunction in perinatal asphyxia varies from 24-60\% [1]. Apart from the clinical presentation, electrocardiography (ECG), echocardiogram and determination of cardiac enzymes are useful tools to detect myocardial involvement. In contrast to adults, recognition of myocardial ischemia is far more difficult in neonates. Only few studies have assessed the myocardial dysfunction with assay of cardiac enzymes and ECG abnormalities $[8,9]$.

Rajakumar et al. [10] demonstrated that C-Troponin assay is useful in evaluating the severity of myocardial damage and outcome in perinatal asphyxia. Kanik et al. [11] studied the assessment of myocardial dysfunction in 
neonates with HIE to predict the mortality. However, there is paucity of reports from our country where mothers often report to hospital quite late with obstetric complications and neonates suffer from birth asphyxia with high mortality. So it becomes imperative to detect myocardial dysfunction as one of the contributing factor and to provide early treatment. Therefore, the present study was undertaken to find out the myocardial involvement in neonates having HIE by the ECG and cardiac enzymes (CK-MB, Troponin I) changes and its correlation with various degree of HIE and outcome.

\section{Patients and methods}

This was a prospective study conducted at a tertiary care centre of a teaching hospital during the period of February, 2010 to January, 2011. The protocol of the study was approved by the Institute Ethics Committee and written informed consent for inclusion was obtained from the parents of each neonate. Sixty inborn neonates at term gestation, who suffered from perinatal asphyxia and developed to hypoxic ischemic encephalopathy, as defined by Levene staging [12], were included. APGAR score of newborns was evaluated at 1, 5 and 10 minutes and they were resuscitated as per NRP guidelines [13]. Cases with congenital heart diseases, major central nervous system malformations and neonatal sepsis were excluded. All the neonates were managed in NICU as per hospital protocol. They were given oxygen by hood (5-6 l/min), nasal continuous positive airway pressure, mechanical ventilation (based on saturation of oxygen (SpO2) and Arterial Blood Gas findings), intravenous fluids, vitamin $\mathrm{K}$, inotropes (Dopamine and/or Dobutamine each by $1-20 \mu \mathrm{g} / \mathrm{kg} / \mathrm{min}$ ) and anticonvulsants (Phenobarbitone $20 \mathrm{mg} / \mathrm{kg}$ as loading dose, followed by $3-5 \mathrm{mg} / \mathrm{kg} /$ day, and phenytoin sodium was also added with same dose in non-responder to phenobarbitone), wherever required. First line antibiotics (cefotaxime and gentamycin) were given to those cases where risk factors for sepsis were present and required mechanical ventilation. Feeding was started once patient showed improvement, initially started as nasogastric feeding and then followed by spoon or breast feeding.

A 12-lead ECG was recorded and $4 \mathrm{ml}$ of venous blood was collected for cardiac enzymes estimation in each asphyxiated neonates within 72 hours of life. Infants with ECG changes of grade 1 or 2 were diagnosed to have mild, whereas those with changes of grades 3 or 4 were considered to have severe injuries. The grading was done as per criteria defined by Jedeikin et al. [14].

Grade1 - with flat or inverted $\mathrm{T}$ waves on 1 or 2 leads except AVR.

Grad 2- with flat or inverted T-waves in 3 or more leads except AVR.
Grade 3- with flat or inverted T-waves in 3 or more leads and either ST depression or elevation $>2 \mathrm{~mm}$ in at least two chest leads or $>1 \mathrm{~mm}$ in at least two standard leads, or a Q-wave abnormality of duration $>0.02 \mathrm{~s}$ or amplitude $>25 \%$ of $\mathrm{R}$ wave in one anterior or three related chest leads.

Grad 4- presence of classical segmental infarction with abnormal Q-wave and markedly elevated ST segment or complete left bundle branch block.

Creatine kinase-Total (CK-Total), Creatine kinase-MB (CK-MB) were measured by quantitative determination based on immune-inhibition IFCC methodology (Agappe diagnostics limited) using semi auto-analyzer. The Calbiotech cTnI ELISA was used for the quantitative determination of cardiac Troponin I from samples. The cTnI ELISA is based on the principal of a solid phase ELISA. . Specimen which could not be assayed within 24 hrs was frozen at $-20{ }^{\circ} \mathrm{C}$ and was stable for 6 months.

A chest X-ray was taken in all patients. The serum which was collected from patient were also analysed for other hematological and biochemical investigations like PCV, total and differential leukocyte count, urea, creatinine, sodium, potassium, calcium and blood sugar.

\section{Statistical analysis}

Differences in mean of quantitative data among different stages of HIE were compared by Analysis of Variance (ANOVA) and proportions by Chi-Square tests. Median values of CK total, CK-MB and troponin I were compared by Kruskal- Wallis test and post-hoc analysis was done to find out the difference between the two parameters. A $p$ value of $<0.05$ was considered as statistically significant.

\section{Results}

The basic characteristics of neonates according to various HIE stages are presented in Table 1. It was observed that none of the parameters showed significant difference among different stages of HIE. The HIE staging in relation to various natal factors is shown in Table 2 , and it showed that color of liquor and mode of delivery did not affect the development of different stages of HIE. However, modes of resuscitation and Apgar scores at 1, 5 and 10 minutes were statistically significant among different stages of HIE. Seventeen (28.3\%) neonates required initial steps of resuscitation and in 43 (71.6\%) bag and mask ventilation was given.It was switched over to bag and tube ventilation in 6 cases as they required prolonged ventilation, in addition 4 (6.6\%) needed chest compression also.

The abnormalities in X-ray chest, ECG and cardiac enzyme are presented in Table 3. The chest X-ray was abnormal and showed features of meconium aspiration 
Table 1 Basic characteristics of neonates and HIE staging

\begin{tabular}{|c|c|c|c|c|c|}
\hline \multirow[t]{2}{*}{ Parameters } & \multirow[t]{2}{*}{ Categories } & \multicolumn{3}{|c|}{ HIE Stage } & \multirow[t]{2}{*}{$\mathrm{p}$} \\
\hline & & Mild $(n=13)$ & Moderate $(n=27)$ & Severe $(n=20)$ & \\
\hline \multirow[t]{2}{*}{ Gender } & Male & $11(84 \%)$ & $21(77 \%)$ & $17(85 \%)$ & \multirow[t]{2}{*}{$0.780^{*}$} \\
\hline & Female & $2(16 \%)$ & $6(23 \%)$ & $3(15 \%)$ & \\
\hline \multirow[t]{3}{*}{ Registration Status } & Booked & $0(0 \%)$ & $1(3.7 \%)$ & $1(5 \%)$ & \multirow[t]{3}{*}{$0.729^{*}$} \\
\hline & Registered & $1(7.6 \%)$ & $1(3.7 \%)$ & $0(0 \%)$ & \\
\hline & Unbooked & $12(92.4 \%)$ & $25(92 \%)$ & 19 (95\%) & \\
\hline \multirow[t]{2}{*}{ Gestational age } & Term & $8(62 \%)$ & $23(85 \%)$ & $16(80 \%)$ & \multirow[t]{2}{*}{$0.230^{*}$} \\
\hline & Post dated & $5(38 \%)$ & $4(15 \%)$ & $4(20 \%)$ & \\
\hline \multirow[t]{2}{*}{ Antenatal complications } & No & $12(92 \%)$ & $18(67 \%)$ & $14(70 \%)$ & \multirow[t]{2}{*}{$0.210^{*}$} \\
\hline & Yes & $1(8.0 \%)$ & $9(33 \%)$ & $6(30 \%)$ & \\
\hline \multirow[t]{2}{*}{ Obstetric Problems } & No & $13(100 \%)$ & $25(92 \%)$ & $20(100 \%)$ & \multirow[t]{2}{*}{$0.282^{*}$} \\
\hline & Yes & $0(0 \%)$ & $2(7.4 \%)$ & $0(0 \%)$ & \\
\hline Birth weight (g) & & $2826.92 \pm 446.1$ & $3111.11 \pm 437.94$ & $2875 \pm 331.46$ & $0.06^{* *}$ \\
\hline Length (cm) & & $49.58 \pm 2.02$ & $50.3 \pm 3.05$ & $49 \pm 2.2$ & $0.241^{* *}$ \\
\hline Head circumference $(\mathrm{cm})$ & & $34.31 \pm 1.49$ & $34.07 \pm 1.64$ & $33.75 \pm 1.25$ & $0.558^{* *}$ \\
\hline Maternal age (yr) & & $22.62 \pm 3.01$ & $24.15 \pm 3.98$ & $23.45 \pm 4.55$ & $0.521^{* *}$ \\
\hline Maternal weight (kg) & & $58 \pm 8.11$ & $56.07 \pm 5.92$ & $58.0 \pm 8.4$ & $0.587^{* *}$ \\
\hline
\end{tabular}

$\mathrm{n}=$ Number of cases, ${ }^{*}$ Chi-square test, ${ }^{* *}$ ANOVA.

in $11(18.3 \%)$ cases. ECG changes were observed in 46 (76.7\%) neonates; of these 19 (41.3\%) had grade I, 13 (28.2\%) grades II and III each and 1 (2.1\%) grade IV abnormalities. Six neonates with mild HIE while 20 each in moderate and severe HIE had abnormal ECG and changes among different stages of HIE were significant $(P=0.002)$. The cardiac enzymes levels were considered abnormal when it were above our reference laboratory values (CK Total $>190 \mathrm{U} / \mathrm{l}, \mathrm{CK}-\mathrm{MB}>25 \mathrm{U} / \mathrm{l}$ and troponin $\mathrm{I}>0.05 \mathrm{ng} / \mathrm{ml})$. The serum level of enzyme CK Total was raised in 54 (90\%), while CK- MB was raised in 52 $(86.6 \%)$ neonates with marked elevation $(>100 \mathrm{U} / \mathrm{L})$ in $34(56.6 \%)$. The troponin I was also raised in $48(80 \%)$ cases. The mean levels of CK Total, CK-MB and troponin I were $1176.8 \mathrm{U} / \mathrm{l}, 147.5 \mathrm{U} / \mathrm{l}$ and $1.4 \mathrm{ng} / \mathrm{ml}$, respectively. Their levels showed further rise with increasing severity of HIE and the severe HIE group had significantly higher level in comparison to mild and moderate HIE cases $(\mathrm{P}=0.02,<0.001$ and 0.004 , respectively). (Figure 1)

Table 2 HIE staging in relation to natal factors

\begin{tabular}{|c|c|c|c|c|c|}
\hline \multirow[t]{2}{*}{ Birth Details } & \multirow[t]{2}{*}{ Categories } & \multicolumn{3}{|c|}{ HIE Stage } & \multirow[t]{2}{*}{$\mathbf{P}$} \\
\hline & & Mild $(n=13)$ & Moderate $(n=27)$ & Severe $(n=20)$ & \\
\hline \multirow[t]{2}{*}{ Liquor } & Clear & $3(23 \%)$ & $17(63 \%)$ & $10(50 \%)$ & $0.061^{*}$ \\
\hline & Meconium & $10(77 \%)$ & $10(37 \%)$ & $10(50 \%)$ & \\
\hline \multirow[t]{3}{*}{ Modes of delivery } & Normal & $10(77 \%)$ & $19(70.4 \%)$ & $14(70 \%)$ & $0.900^{*}$ \\
\hline & Caesarean & $3(23 \%)$ & $6(22.2 \%)$ & $5(25 \%)$ & \\
\hline & Instrumental & $0(0 \%)$ & $2(7.4 \%)$ & $1(5 \%)$ & \\
\hline \multirow[t]{3}{*}{ Details of resuscitation } & Initial steps & $3(23 \%)$ & $13(48 \%)$ & $1(5 \%)$ & $0.009^{*}$ \\
\hline & Bag and Mask $\neq$ Chest compression & $10(77 \%)$ & $14(52 \%)$ & $19(95 \%)$ & \\
\hline & & $0(0 \%)$ & $0(0 \%)$ & $4 \neq$ & \\
\hline Apgar score-1 min & & $3.23 \pm 0.83$ & $3.11 \pm 0.64$ & $2.55 \pm 0.6$ & $0.007^{* *}$ \\
\hline Apgar score-5 min & & $5.08 \pm 0.49$ & $4.78 \pm 0.58$ & $4.1 \pm 0.79$ & $<0.001^{* *}$ \\
\hline Apgar score-10 min & & $7.46 \pm 0.88$ & $6.96 \pm 0.9$ & $5.5 \pm 1.15$ & $<0.001^{* *}$ \\
\hline
\end{tabular}

$\neq \ln 6$ neonates, bag and mask was switched over to bag and tube ventilation and 4 cases required chest compression also $n=$ Number of cases, ${ }^{*}$ Chi-square test, ** ANOVA. 
Table 3 X-ray chest, ECG and cardiac enzymes in study subjects

\begin{tabular}{|c|c|c|c|}
\hline Investigations & Categories & $\begin{array}{l}\text { Number of } \\
\text { patients }\end{array}$ & Percentage \\
\hline \multirow[t]{2}{*}{ Chest X-ray } & Normal & 49 & 81.7 \\
\hline & Abnormal & 11 & 18.3 \\
\hline \multirow[t]{2}{*}{ E.C.G } & Abnormal & 46 & 76.7 \\
\hline & Normal & 14 & 23.3 \\
\hline \multirow[t]{4}{*}{ Grading of E.C.G } & Grade1 & 19 & 41.3 \\
\hline & Grade2 & 13 & 28.2 \\
\hline & Grade3 & 13 & 28.2 \\
\hline & Grade4 & 1 & 2.1 \\
\hline \multirow[t]{2}{*}{ CK Total (U/I) } & $<190$ & 6 & 10 \\
\hline & $>190$ & 54 & 90 \\
\hline \multicolumn{2}{|l|}{ Mean \pm SD of CK Total } & \multicolumn{2}{|l|}{$1176.8 \pm 1023.1$} \\
\hline \multirow[t]{3}{*}{ CK MB (U/I) } & $<25$ & 8 & 13.3 \\
\hline & $25-100$ & 18 & 30 \\
\hline & $>100$ & 34 & 56.6 \\
\hline \multicolumn{2}{|l|}{ Mean $\pm S D$ of CK MB } & \multicolumn{2}{|l|}{$147.5 \pm 161.0$} \\
\hline \multirow[t]{2}{*}{ Troponin I (ng/ml) } & $\leq 0.5$ & 12 & 20 \\
\hline & $>0.5$ & 48 & 80 \\
\hline \multicolumn{2}{|c|}{ Mean \pm SD of Troponin I } & \multicolumn{2}{|l|}{$1.4 \pm 1.1$} \\
\hline
\end{tabular}

Three babies ( 1 mild and 2 moderate HIE) left against medical advice because their parents had financial constraints in continuing the medication in hospital. Sixteen of $57(28 \%)$ neonates died during hospital stay between 30 to $264 \mathrm{hr}$ of post natal life. They belonged to severe HIE stage and needed mechanical ventilation, inotropes and anticonvulsants in addition to other supportive measures. Outcome of newborns with HIE in relation to ECG, CK-Total, CK-MB and troponin I are shown in Table 4. The non- survivors had significantly high proportion of abnormal ECG $(\mathrm{p}=0.01)$, raised levels of CK-MB $(\mathrm{p}=0.03)$ and troponin I $(\mathrm{p}=0.01)$ in comparison to survivors. However, no such relationship was observed with CK-Total level in these neonates.

\section{Discussion}

As such various demographic data such as gender, birth weight, length, head circumference, maternal registration status, gestational age, antenatal complications, obstetric problems, maternal age and weight were evenly distributed among different stages of HIE.

Meconium stained amniotic fluid was present in 50\% of cases which is similar to the finding of Martin-Ancel et al. [15]. Modes of delivery and meconium staining of liquor did not affect the progression to different stages of HIE in neonates with birth asphyxia.

Apgar score at 1 minute was $<3$ in $14(23.3 \%)$ and 3-5 in 46(76.7\%) neonates. Apgar score at 5 minute was 3 to

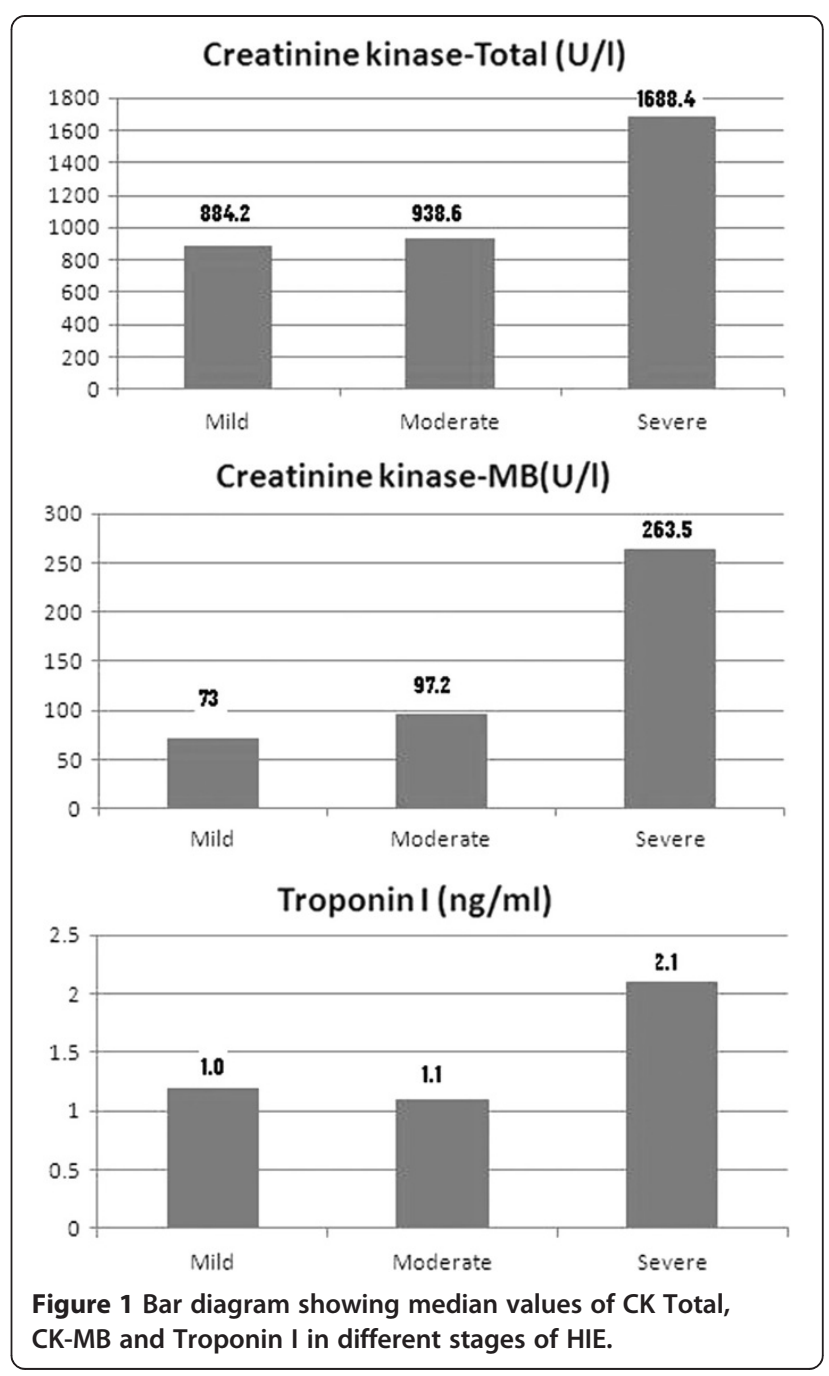

5 in $57(95 \%)$ and $>5$ in 3(5\%) cases. In a study by Shah et al. [4], Apgar score at 5 minute was less than 5 in (63.12\%) neonates. Martin-Ancel et al. [15] also reported Apgar score at 1 minute was 4 in $70 \%$ of cases which is similar to our study. However, Apgar scores at 5 minute were $\geq 7$ in $46 \%, 4$ to 6 in $37 \%$, and $\leq 3$ in $14 \%$ of patients which is in contrast to our findings. In our study, 41 $(68.3 \%)$ neonates had seizures. Shah et $\mathrm{al}^{4}$ documented seizures or coma in $87 \%$ of cases.

The various clinical features related to cardiac dysfunction documented were respiratory distress, congestive cardiac failure and shock. We found respiratory distress in 32(53.3\%) and shock in 29(48.3\%) cases. One neonate had congestive cardiac failure which was present in HIE stage III group. Rajakumar et al. [10], reported respiratory distress in 20 (66.7\%), cardiac failure in $11(36.7 \%)$ and cardiogenic shock in 5 (16.7\%); while 8 babies were asymptomatic. However, Mandal et al. [16] found congestive cardiac failure in higher percentage 
Table 4 Outcome of neonates with HIE in relation to ECG and cardiac enzymes

\begin{tabular}{|c|c|c|c|c|}
\hline Parameters & Categories & Survivors $(n=41)$ & Non-survivors $(n=16)$ & $\mathrm{P}^{*}$ \\
\hline \multirow[t]{2}{*}{ ECG } & Normal & $13(31.7 \%)$ & $0(0 \%)$ & 0.010 \\
\hline & Abnormal & $28(68.3 \%)$ & $16(100 \%)$ & \\
\hline \multirow[t]{2}{*}{ CK-Total(U/L) } & Normal & $4(9.8 \%)$ & $1(6.3 \%)$ & 0.674 \\
\hline & Abnormal & $37(90.2 \%)$ & 15 (93.8\%) & \\
\hline \multirow[t]{2}{*}{ CK-MB(U/L) } & Normal & $10(24.4 \%)$ & $0(0 \%)$ & 0.030 \\
\hline & Abnormal & $31(75.6 \%)$ & $16(100 \%)$ & \\
\hline \multirow[t]{2}{*}{ Troponin-I (ng/dl) } & Normal & $12(29.3 \%)$ & $0(0 \%)$ & 0.015 \\
\hline & Abnormal & 29 (70.7\%) & $16(100 \%)$ & \\
\hline
\end{tabular}

${ }^{*}$ Chi-square test.

(36\%) of their cases. They found shock in $44 \%$, which is similar to our observation.

Pulmonary infiltrates suggestive of meconium aspiration were present in X-ray chest of $11(18.3 \%)$ neonates and of these, 9 cases belonged to severe HIE. ECG changes were present in $46(76.7 \%)$ neonates. Grade 1 ECG changes were seen in 19(41.30\%), grades 2 and 3. in $13(28.26 \%)$ cases each. Rajakumar et al. [10] reported ECG changes in almost similar percentage (73.3\%) of cases. The most common finding in their study was ' $\mathrm{T}$ ' wave inversion (36.7\%) followed by ' $\mathrm{T}$ ' wave flattening (33.3\%), which is equivalent, to grade 1 ECG change. These ECG abnormalities indicate myocardial ischaemia due to birth asphyxia in neonates.

Mean CK total level, CK MB and troponin I were $1176.8 \mathrm{IU} / \mathrm{l}, 147.5 \mathrm{IU} / \mathrm{l}$ and $1.4 \mathrm{ng} / \mathrm{ml}$, respectively. Mandal et al. [16] and Warburton et al [17] reported CK-MB values as high as a $823.5 \mathrm{IU} / \mathrm{l}$ and $328 \mathrm{IU} / \mathrm{l}$, respectively. Rajakumar et al [10] reported lower mean CK-MB level (121 IU/l) in their study. The enzyme levels showed significant rise with increasing severity of HIE; indicating more myocardial ischaemia in severe HIE than mild and moderate cases.

Primhak et al [18] studied serial electrocardiogram and CK-MB in term infants and found that CK-MB was associated with myocardial injury in asphyxiated infants. However, Omokhodion et al [19] concluded that specificity of CK-MB as a marker of myocardial injury in asphyxiated newborns is possible but remains uncertain. Borke and co-workers [20] showed cardiac troponin I to be a reliable marker of myocardial necrosis. Thus previous studies showed that perinatal asphyxia is associated with myocardial dysfunction. However, they did not provide information regarding interventions performed in the delivery room and moreover study was conducted prior to the introduction of standardized neonatal resuscitation [13]:

The influence of hypoxemia related myocardial dysfunction in the newborn occurs in 30\% of asphyxiated neonetes [15] and is thought to be secondary to direct effect of ischaemia on cardiac myocytes. Enzymatic indicators of myocardial injury in the asphyxiated newborns are elevated and often associated with electrocardiographic changes. The measurement of cardiac troponin I may have a role in the early identification of neonates with myocardial damage secondary to ischaemia. However, cardiac abnormalities often are under diagnosed and require a high index of suspicion.

We found a clear relationship between outcome of asphyxiated newborns and alterations in ECG and enzymatic parameters as significantly higher proportions of non- survivors had ECG abnormalities and raised levels of CK-MB and troponin I. Patients showing more severe hypoxic damage also reflected the striking changes in these parameters. Hypoxia is responsible for multiorgan dysfunction causing deaths, but particularly results in myocardial damage despite "preferential" myocardial perfusion $[5,21]$. These markers may be useful in providing appropriate cardiovascular support in addition to managing the primary condition.

Thus, it can be concluded that myocardial dysfunction secondary to perinatal asphyxia is more frequent than thought, for which it will be useful to submit asphyxiated neonates to ECG monitoring and assay of cardiac enzyme markers complemented with clinical findings. The early detection and prompt treatment of condition will help in improving prognosis of these asphyxiated newborns.

\section{Conclusions}

This study suggests that significant ECG and cardiac enzymes (CK-total, CK-MB, troponin I) alterations occur in neonates with birth asphyxia having HIE. These features indicate hypoxic damage to myocardium affecting the survival.

\section{What is already known on this topic}

Varying degree of multi organ dysfunction including myocardial involvement in perinatal asphyxia developing HIE can occur. 


\section{What this study adds}

Different grades of ECG and cardiac enzymes abnormalities develop in neonates with HIE and it adversely affect the outcome.

\section{Competing interests}

The authors declare that they have no competing interests.

\section{Acknowledgements}

Authors are thankful to Mr D. Baral, who helped in statistical analysis and Mr. Santosh Bastola for providing graphical presentation of data in the present study.

B. P. Koirala Institute of Health Sciences provided the research grant for carrying out the study.

\section{Author details}

'Departments of Pediatrics and Adolescent Medicine, B.P. Koirala Institute of Health Sciences, Dharan, Nepal. ${ }^{2}$ Departments of Biochemistry, B.P. Koirala Institute of Health Sciences, Dharan, Nepal. ${ }^{3}$ Departments of Obstetrics and Gynecology, B.P. Koirala Institute of Health Sciences, Dharan, Nepal. ${ }^{4}$ Department of Pediatrics, Institute of Medical Sciences, Banaras Hindu University, Varanasi, India.

\section{Authors' contributions}

GSS \& PP- involved in concept and design of the study, JA \& AA-collection and analysis of data, NB- helped in biochemical analysis and OPM- analysis of data and drafting the manuscript. All authors read and approved the final manuscript.

Received: 17 May 2012 Accepted: 23 July 2012

Published: 23 July 2012

\section{References}

1. Adcock LM, Papile LA: Perinatal asphyxia. In Manual of neonatal care. 6th edition. Edited by Cloherty JP, Eichenwald EC, Stark AR. New Delhi: Wolters Kluwer; 2008:518-523.

2. Flores-Nava G, Echevarría-Ybarguengoitia JL, Navarro-Barrón JL, GarcíaAlonso A: Isquemia miocárdica transitoria en el recién nacido con asfixia perinatal (miocardiopatía hipóxica). Biol Med Hosp Infant Mex 1990, 47:809-13.

3. Lee ACC, Mullany LC, Tielsch JM, et al: Risk Factors for Neonatal Mortality due to Birth Asphyxia in Southern Nepal: A Prospective, Community-based Cohort Study. Pediatrics 2008, 121:1381-90.

4. Shah P, Riphagen S, Beyene J, Perlman M: Multiorgan dysfunction in infants with post-asphyxial hypoxic-ischaemic encephalopathy. Arch Dis Child Fetal Neonatal Ed 2004, 89:F152-F155.

5. Pasternak JF: Hypoxic-ischemic brain damage in the term infant. Pediatr Clin North Am 1993, 40:1061-1071.

6. Saili A, Sarna MS, Gathwala G, Kumari S, Dutta AK: Liver dysfunction in severe birth asphyxia. Indian Pediatr 1990, 27:1291-4.

7. Tapia-Rombo CA, Carpio-Hernandez JC, Salazar-Acuna AH, AlvarezVazquez E, Mendoza-Zanella RM, Perez-Olea $\mathrm{V}$, et al: Detection of transitory myocardial ischemia secondary to perinatal asphyxia. Arch Med Res 2000, 31:377-383.

8. Barberi I, Calabro MP, Cordaro S, Gitto E, Sottile A, Prudente D, et al: Myocardial ischaemia in neonates with perinatal asphyxia electrocardiographic, echocardiographic and enzymatic correlations. Eur J Pediatr 1999, 158:742-747.

9. Costa S, Zecca E, De Rosa G, De Luca D, Barbato G, Pardeo M, Romagnoli C: Is serum troponin $\mathrm{T}$ a useful marker of myocardial damage in newborn infants with perinatal asphyxia? Acta Paediatrica 2007, 96:181-184.

10. Rajakumar PS, Bhat BV, Sridhar MG, Balachander J, Konar BC, Narayanan P, et al: Cardiac Enzyme Levels in Myocardial Dysfunction in Newborns with Perinatal Asphyxia. Indian J Pediatr 2008, 75:1223-1225.

11. Kanik E, Ozer EA, Bakilar AR, Aydinlioglu H, Dorak C, Dogrusoz B, et al: Assessment of myocardial dysfunction in neonates with $\mathrm{HIE}:$ is it a significant predictor of mortality? The Journal of maternal-fetal and neonatal medicine 2009, 22:239-242.
12. Levene MI, Kornberg J, Williams THC: The incidence and severity of postasphyxial encephalopathy in full-term infants. Early Hum Dev 1985, 11:21-8.

13. Neonatal Resuscitation Program Guidelines: Neonatal Resuscitation Manual. American Heart Association and American Academy of Pediatrics; 2005.

14. Jedeikin R, Primhak A, Shennan AT, Swyer PR, Rowe RD: Serial electrocardiographic changes in healthy and stressed neonates. Arch Dis Child 1983, 58:605-611.

15. Martin-Ancel A, Garcia-Alix A, Gaya F, Cabanas F, Burgueros M, Quero J: Multiple organ involvement in perinatal asphyxia. J Pediatr 1995, 127:786-793.

16. Mandal Ravi RN, Ruchi G, Kapoor AK: Evaluation of activity of creatine Phosphokinase (CPK) and its Isoenzyme CPK-MB in perinatal asphyxia and its implications for myocardial involvement. Bull NNF 1999, 13:2-7.

17. Warburton $D$, Singer DB, Oh W: Effects of acidosis on the activity of creatine phosphokinase and its isoenzymes in the serum of newborn infants. Pediatrics 1981, 68:195-197.

18. Primhak RA, Jedeikin R, Ellis $G$, et al: Myocardial ischaemia in asphyxia neonatorum. Acta Paediatr Scand 1985, 74:595-600.

19. Omokhodion SI, Losekoot TG, Jaiyesimi F: Serum creatine kinase and creatine kinase-MB isoenzyme activities in perinatally asphyxiated newborns. Eur Heart J 1991, 12:980-984.

20. Borke WB, Munkeby BH, Morkrid L, Thaulow E, Saugstad OD: Resuscitation with $100 \% \mathrm{O}_{2}$ does not protect the myocardium in hypoxic newborn piglets. Arch Dis Child Fetal Neonatal Ed 2004, 89:F156-F160.

21. Agustin L, Katseto SD, Mishra OP, Maria DP: Perinatal hypoxic ischemic encephalopathy: Current and future treatments. Int Pediatr 2000 15:143-151

doi:10.1186/1824-7288-38-33

Cite this article as: Agrawal et al:: Electrocardiographic and enzymatic correlations with outcome in neonates with hypoxic-ischemic encephalopathy. Italian Journal of Pediatrics 2012 38:33.

\section{Submit your next manuscript to BioMed Central and take full advantage of:}

- Convenient online submission

- Thorough peer review

- No space constraints or color figure charges

- Immediate publication on acceptance

- Inclusion in PubMed, CAS, Scopus and Google Scholar

- Research which is freely available for redistribution 